\title{
Radiotherapy increases plasma levels of tumoral cell-free DNA in non-small cell lung cancer patients
}

This article has been corrected. Correction in Oncotarget. 2018; 9:23844-23844.

Shun-ichiro Kageyama ${ }^{1}$, Keiji Nihei ${ }^{1}, K$ Katsuyuki Karasawa ${ }^{1}$, Takeshi Sawada ${ }^{1}$, Fumiaki Koizumi ${ }^{1}$, Shigeo Yamaguchi ${ }^{1}$, Shunsuke Kato ${ }^{1}$, Hidehiro Hojo ${ }^{1}$, Atsuhi Motegi $^{1}$, Katsuya Tsuchihara ${ }^{1}$ and Tetsuo Akimoto ${ }^{1}$

${ }^{1}$ National Cancer Center Hospital East, Kashiwa, Chiba 277-8577, Japan
Correspondence to: Shun-ichiro Kageyama, email: skageyam@east.ncc.go.jp

Keywords: tumoral cell-free DNA; radiotherapy; NSCLC; tumor-specific mutations; digital PCR

Received: November 21, $2017 \quad$ Accepted: March 21, $2018 \quad$ Published: April 10, 2018

Copyright: Kageyama et al. This is an open-access article distributed under the terms of the Creative Commons Attribution License 3.0 (CC BY 3.0), which permits unrestricted use, distribution, and reproduction in any medium, provided the original author and source are credited.

\section{ABSTRACT}

We investigated the plasma levels of tumor-specific cell-free DNA (cfDNA) in 17 stage I-II (early) and IV (advanced) non-small cell lung cancer (NSCLC) patients who underwent radiotherapy. Digital polymerase chain reaction (PCR) and targeted sequencing showed that total and tumor-specific cfDNA levels increased in response to radiotherapy in both early- and advanced-stage NSCLC patients. We detected high copy numbers of epidermal growth factor receptor mutations (L858R and T790M) in the cfDNA samples from stage IV NSCLC patients who underwent stereotactic body radiation therapy to treat brain metastasis related to tyrosine kinase inhibitor (TKI) treatment failure. In conclusion, our study demonstrates that radiotherapy increases tumoral cfDNA levels in the plasma and shows potential to serve as an indicator for diagnosing drug-resistant tumor-related gene mutations in early-stage NSCLC patients or those undergoing molecular targeted therapy.

\section{INTRODUCTION}

Analysis of tumoral cell-free DNA (cfDNA) represents a cost-effective, non-invasive method to detect tumor-related gene mutations and drug resistance in human cancers; higher degree tumor cell necrosis is associated with higher plasma levels of cfDNA [1-6]. Diehl et al. showed that the majority of the tumoral cfDNA fragments represent nucleosomal units (160 to 200 base pairs long) $[7,8,12]$, with half-lives ranging from a few minutes to several hours $[10,13]$. These fragments are cleared in the spleen, liver, and kidneys [9-11], thought the specific cfDNA clearance mechanisms are not well understood.

CfDNA analysis has been used to assess drug resistance in non-small cell lung cancer (NSCLC) [15]. A phase III clinical trial (NCT02282267) used digital polymerase chain reaction (PCR) analysis to quantify dynamic changes in epidermal growth factor receptor (EGFR) mutations in NSCLC patients in patient cfDNA samples. Most studies have used PCR to make diagnoses based on known genetic variations in cfDNA samples, which have a sensitivity of $70-90 \%$ and a specificity of $90 \%[2,8,14,15]$.

Next-generation sequencing of cfDNA samples from untreated stage IV NSCLC patients has shown promise as a diagnostic tool $[16,17]$. However, cfDNA detection is difficult in early-stage cancer patients or cancer patients undergoing therapy. This is critical because nearly $50 \%$ of NSCLC patients are diagnosed with early stage disease. Recently, a targeted sequencing approach with $10,000 \times$ coverage to detect somatic driver mutations in cfDNA from early-stage NSCLC patients ( IA, IB, and IIA) showed a concordance rate of $39.8 \%$ with sensitivity and specificity of $53.8 \%$ and $47.3 \%$, respectively $[2,18,19]$. Therefore, there is a need to increase tumoral cfDNA levels in earlystage cancer patients and those undergoing treatment in order to optimally use cfDNA analysis for diagnostic purposes.

Radiotherapy is widely used for cancer treatment and palliative care because targeted irradiation increases tumor cell apoptosis. NSCLC patients undergo stereotactic body radiotherapy (SBRT), chemo radiotherapy, or 
palliative radiotherapy at different stages of the disease. Since higher levels of cell-free DNA and CTC have been observed in the plasma of patients during chemo radiotherapy $[7,20]$, we postulated that tumoral cfDNA analysis after radiotherapy would be useful to diagnose cancer-related mutations and chemo resistance in early stage cancer patients and those undergoing treatment.

Radiation doses vary widely among cell lines, animal models, and clinical settings. In a laboratory setting, cancer cell lines are irradiated with 2-20 Gy/fraction (fr) and undergo apoptosis within 24-48 h [21, 22]. In animal experiments, the radiation doses are higher (10 $\mathrm{Gy} / 5$ fr to $30 \mathrm{~Gy} / 15 \mathrm{fr}$ ) and tumor reduction is observed within 1-2 weeks after irradiation [23-25]. In the clinic, radiation doses vary between $60 \mathrm{~Gy} / 30 \mathrm{fr}$ and $50 \mathrm{~Gy} / 4$ $\mathrm{fr}$, and maximal tumor reduction is observed within 4-8 weeks after irradiation $[26,27]$. In the present study, we determined the effects of radiotherapy on the levels of tumoral cfDNA in 17 NSCLC patients (stages I and IV).

\section{RESULTS}

We enrolled seventeen patients with suspected NSCLC that underwent curative or palliative radiotherapy between July 2013 and July 2015. Eleven stage I NSCLC patients rejected surgery and chose radiotherapy, whereas, the remaining 6 stage IV NSCLC patients were positive for $E G F R$ mutations and showed new brain metastasis, suggesting failure of tyrosine kinase inhibitor (TKI) treatment. The 11 stage I primary NSCLC patients were treated with curative SBRT or 3D-CRT, whereas, the six stage IV NSCLC patients received palliative SBRT against brain metastasis. A high-radiation dose was delivered specifically to the cancer tissue as routine therapy for all patients as shown in Supplementary Figure 1. The experimental strategy for this study is shown in Figure 1. The clinicopathological features of the 17 patients are described in Table 1.

We detected cfDNA in all patients, and the total circulating cfDNA increased in response to radiotherapy in 12 out of 17 patients (Table 1; Figures 2-3). The median circulating cfDNA concentrations at pre-RT, RT and post-RT in stage I-II NSCLC patients were 5.75, 24.75, and $3.7 \mathrm{ng} / \mathrm{mL}$, respectively (Figure 4A). This demonstrated that the total cfDNA levels increased in response to radiotherapy in stage I NSCLC patients. The median circulating cfDNA concentrations at preRT, RT and post-RT in stage IV NSCLC patients were $11.53,95.0$, and $51.83 \mathrm{ng} / \mathrm{mL}$, respectively (Figure 4B). Tumor-specific cfDNA levels were confirmed using digital PCR analysis with matched plasma cfDNA from patients positively diagnosed with EGFR mutation and who provided sufficient DNA for sequence analysis. The relative cfDNA concentration increased significantly between pre-radiotherapy and radiotherapy in stage I-II and stage IV NSCLC patients $(P<0.05$; Figure 4A-4B).
Moreover, post-radiotherapy cfDNA levels were lower than the pre-radiotherapy levels in stage I-II NSCLC patients. The increase in cfDNA levels was detected at 24 $\mathrm{h}$ after irradiation and peaked at 7 days after radiotherapy.

Next, we determined the cancer-specific gene mutations in $E G F R$, a dominant driver in lung adenocarcinomas. We performed digital PCR analysis of cfDNA from four patients diagnosed with adenocarcinoma bearing the EGFR L858R mutation ( $n=2)$ or EGFR exon 19 deletion $(n=2)$. The copy numbers for these $E G F R$ mutations increased from $0,20866,44194$, and 64282 copies/mL before radiotherapy to $10562,139579,363269$, and 2122718 copies $/ \mathrm{mL}$, respectively after radiotherapy (Table 2).

The allele frequencies for the EGFR mutations increased from $0,0.5,0.2$, and $0.6 \%$ to $0.9,2.3,0.4$, and $6.4 \%$, respectively (Table 2 ). The T790M mutation in case 16 cfDNA sample was detected only after radiotherapy. The diagnosis of case 16 showed lung adenocarcinoma with the L858R mutation and received SBRT for brain metastasis, which showed failure of TKI treatment. Finally, we performed targeted deep sequencing to further analyze mutated genes in the cfDNA samples from NSCLC patients. We obtained sufficient cfDNA from six cases $(1,2,12,15,16$, and 17) after radiotherapy for sequencing and digital PCR analysis (>60 ng). The results are shown in Table 2. EGFR mutations were detected in post-radiotherapy samples from the four EGFR mutationpositive NSCLC patients. Only two out of four cases (case 15, case 17) showed these mutations in their preradiotherapy samples. Furthermore, we detected EGFR G719C mutation in the post-radiotherapy sample from patient (case 1), whose biopsy was not performed and the $E G F R$ mutation status was unknown previously. In case 16, we detected the EGFR L747S mutation, which is known to confer resistance to TKIs. We also observed an increase in allele frequency and tumoral DNA content in 5 out of 6 cases $(2,12,15,16$ and 17).

\section{DISCUSSION}

Tumoral cfDNA analysis is useful for making cancer diagnoses and for assessing cancer-related drug resistance. However, this strategy is not viable in early stage cancer patients and those undergoing cancer treatments because the concentration of cfDNA is limited. In this study, therefore, we demonstrated that radiotherapy increases tumoral cfDNA levels in the plasma of stage I and IV NSCLC patients. We also demonstrated drug resistancerelated $E G F R$ gene mutations in the cfDNA of stage IV NSCLC patients that experience distal metastasis recurrence as a result of drug failure.

We subjected patients to radiotherapy $(50 \mathrm{~Gy} / 4 \mathrm{fr}$, $75 \mathrm{~Gy} / 25 \mathrm{fr}, 35 \mathrm{~Gy} / 3 \mathrm{fr}$, or $23 \mathrm{~Gy} / 1 \mathrm{fr}$ ) and analyzed total cfDNA levels in pre-RT, RT and post-RT plasma samples daily. We observed higher total and tumoral cfDNA 
levels at $24 \mathrm{~h}$ after irradiation than in pre-RT samples in stage I-II NSCLC patients. The total and tumoral cfDNA levels peaked at 7 days after irradiation. This suggested that cancer tissue apoptosis occurs within $24 \mathrm{~h}$ after radiotherapy and is similar to the kinetics of apoptosis in the cancer cell lines. Clinically, tumor reduction is observed at 4-8 weeks after radiotherapy as defined response evaluation criteria in solid tumours:Revised RECIST guideline (version 1.1). This large time lag between effects at a cellular level and at an anamical level is probably due to radiation-induced inflammation and edema, which delays visual detection (e.g., by CT scan) of tumor reduction. We also observed elevated cfDNA levels after irradiation with a total dose of 30 Gy or less in 12 cases. Low irradiation doses of $8 \mathrm{~Gy} / 1 \mathrm{fr}$ to $30 \mathrm{~Gy} / 10 \mathrm{fr}$ are used for palliative treatment [28-30].

Radiation-induced apoptosis generates $50-300 \mathrm{~kb}$ fragments of DNA in cell lines [31]. However, cfDNA levels have not been determined in patients that have undergone radiotherapy. In this study, we quantified cfDNA levels after irradiation using digital PCR and amplicon sequencing. In a previous study, the status of drug resistance was monitored by determining the levels of fused cancer-related genes with $>10 \mathrm{ng}$ total cfDNA and allele frequency of $0.1 \%$ [16]. However, total cfDNA levels are limiting in early-stage cancer patients and those undergoing therapy. In our study, we obtained $>10 \mathrm{ng}$ cfDNA in 6 out of 11 stage I-II NSCLC patients that underwent radiotherapy. Moreover, we obtained $>10 \mathrm{ng}$ cfDNA in 9 out of 10 patients by increasing the whole blood volume to $14 \mathrm{~mL}$, thereby augmenting allele frequency by about 10 fold. A previous report indicated that a depth of $>10000 \times$ was required for cfDNA analysis in early cancer [19]. Moreover, increasing the allele frequency is cost-effective and extends the sequence (e.g., exome) analysis.

Radiotherapy is as effective as surgery for patients with stage I-II NSCLC [32]. However, surgery is preferred because it also provides specimens for comprehensive clinical diagnosis, especially in patients from whom biopsy specimens cannot be obtained. In some cases, patients undergoing radiation therapy experience functional decline in breathing and require anticoagulant medical treatment. Moreover, biopsy specimens can be obtained endoscopically in only $50-70 \%$ of cancer patients [33]. Detection of cancer-specific DNA mutations can diagnose secondary cancer and pulmonary metastasis in stage I-II patients that have undergone curative radiotherapy. This information is essential to make an informed decision regarding the next course of treatment. For example, follow-up CT is required every 3 months after SBRT. However, if benign nodule is confirmed, follow-up CT is required only once a year. Furthermore, distant metastasis recurrence is more prevalent in NSCLC patients with $E G F R$ mutations than patients with wild-type EGFR [34, 35]. This information is useful for physicians and radiologists to follow-up cancer patients.

Molecular targeted therapy is preferred for stage IV patients with anaplastic lymphoma kinase (ALK) fusion or EGFR mutations. However, cancer cells with

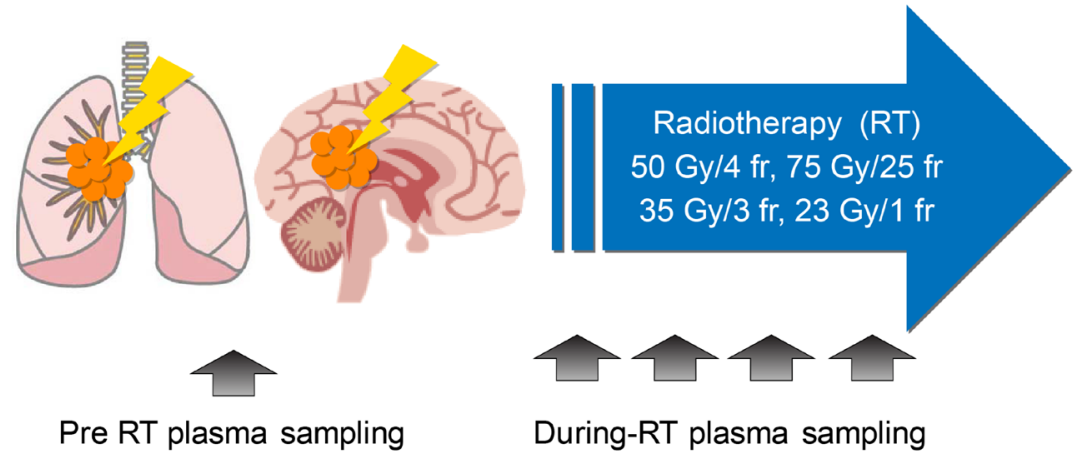

A first fraction, $1 / 4,1 / 2,3 / 4$, total dose finished 1 week, 1 month after RT finished

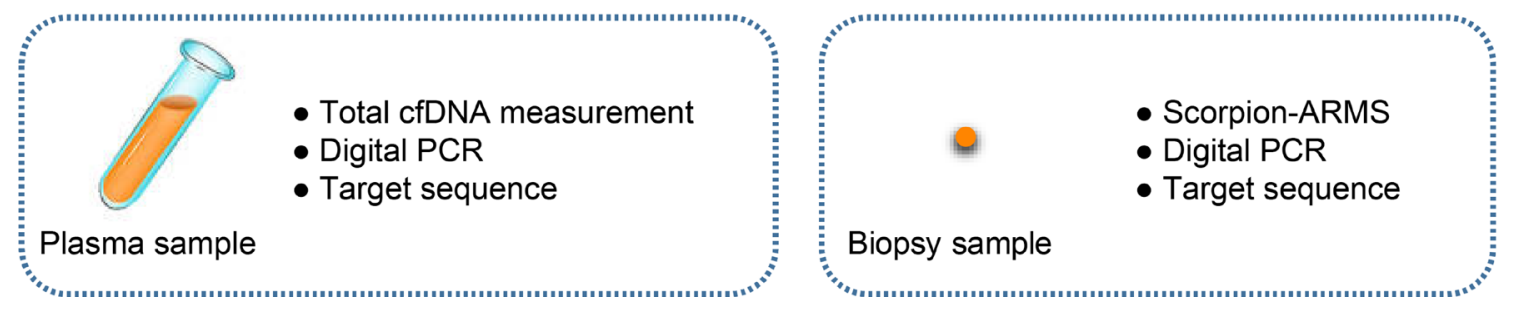

Figure 1: Schematic representation of the experimental strategy to analyze plasma cfDNA levels in NSCLC patients in response to radiotherapy. The plasma and biopsy samples were obtained from NSCLC patients during ( $24 \mathrm{~h})$ and post-radiotherapy (at 1 week and 1 month) and compared with pre-radiotherapy samples. Total cfDNA levels and tumor-specific cfDNA levels were estimated by digital PCR and targeted sequencing. Note: cfDNA, cell-free DNA; fr, fraction; RT, radiotherapy. 
Table 1: Clinical characteristics of NSCLC patients

\begin{tabular}{|c|c|c|c|c|c|c|c|}
\hline Case & Age/Gender & TNM & Stage & Biopsy & Histology & EGFR mutation & Radiation dose \\
\hline Case 1 & $70 / \mathrm{F}$ & T1bN0M0 & IA & - & $\mathrm{ad}$ & N.D. & $75 \mathrm{~Gy} / 25 \mathrm{fr}$ \\
\hline Case 2 & $90 / \mathrm{M}$ & T2aN0M0 & IB & + & $\mathrm{ad}$ & L858R & $75 \mathrm{~Gy} / 25 \mathrm{fr}$ \\
\hline Case 3 & $84 / \mathrm{M}$ & T1aN0M0 & IA & - & ad & N.D. & $75 \mathrm{~Gy} / 25 \mathrm{fr}$ \\
\hline Case 4 & $84 / F$ & T2aN0M0 & IB & + & $\mathrm{ad}$ & N.D. & $75 \mathrm{~Gy} / 25 \mathrm{fr}$ \\
\hline Case 5 & $73 / \mathrm{F}$ & T1aN0M0 & IA & - & $\mathrm{ad}$ & Wild & $50 \mathrm{~Gy} / 4 \mathrm{fr}$ \\
\hline Case 6 & $91 / \mathrm{F}$ & T1aN0M0 & IA & - & ad & N.D. & $50 \mathrm{~Gy} / 4 \mathrm{fr}$ \\
\hline Case 7 & $85 / \mathrm{M}$ & T2aN0M0 & IB & + & ad & N.D. & $50 \mathrm{~Gy} / 4 \mathrm{fr}$ \\
\hline Case 8 & $73 / \mathrm{F}$ & T2aN0M0 & IB & + & NSCLC & N.D. & $50 \mathrm{~Gy} / 4 \mathrm{fr}$ \\
\hline Case 9 & $67 / \mathrm{M}$ & T1aN0M0 & IV & - & ad & N.D. & $50 \mathrm{~Gy} / 4 \mathrm{fr}$ \\
\hline Case 10 & $83 / \mathrm{M}$ & T1aN0M0 & IA & + & ad & N.D. & $50 \mathrm{~Gy} / 4 \mathrm{fr}$ \\
\hline Case 11 & $85 / \mathrm{F}$ & T1aN0M0 & IA & - & $\mathrm{ad}$ & N.D. & $45 \mathrm{~Gy} / 4 \mathrm{fr}$ \\
\hline Case 12 & $63 / \mathrm{F}$ & T2bN0M01b (BRA) & IV & + & adsq & exon 19 del. & $35 \mathrm{~Gy} / 3 \mathrm{fr}$ \\
\hline Case 13 & $40 / \mathrm{M}$ & $\begin{array}{l}\text { T4NXM1b } \\
\text { (PUL, OSS, BRA) }\end{array}$ & IV & + & $\mathrm{ad}$ & exon 19 del. & $35 \mathrm{~Gy} / 3 \mathrm{fr}$ \\
\hline Case 14 & $52 / \mathrm{M}$ & T1aN3M1 (BRA, PUL) & IV & + & $\mathrm{ad}$ & T790M & $23 \mathrm{~Gy} / 1 \mathrm{fr}$ \\
\hline Case 15 & $71 / \mathrm{M}$ & $\begin{array}{l}\text { T3NXM1b (PUL, BRA, } \\
\text { OSS, HEP, SPL) }\end{array}$ & IV & + & $\mathrm{ad}$ & L858R & $23 \mathrm{~Gy} / 1 \mathrm{fr}$ \\
\hline Case 16 & $45 / \mathrm{M}$ & $\begin{array}{l}\text { T2aN3M1b } \\
\text { (OSS, BRA, HEP) }\end{array}$ & IV & + & ad & L858R & $23 \mathrm{~Gy} / 1 \mathrm{fr}$ \\
\hline Case 17 & $84 / \mathrm{F}$ & T3N2M1b (BRA) & IV & + & NSCLC & exon 19 del. & $23 \mathrm{~Gy} / 1 \mathrm{fr}$ \\
\hline
\end{tabular}

Note: ad., adenocarcinoma; adsq. adenosquamous; Stage, cancer stages I-IV; fr, fraction; N.D., not determined; NSCLC, non-small cell lung cancer; TNM, classification system of malignant tumors.

Metastasis site: PUL, lung; BRA., brain; HEP., liver; OSS., bone; SPL., spleen.

EGFR T790M and $A L K$ L1196M mutations acquire drug resistance. The second-generation ALK repressor (Alectinib) for the $A L K \mathrm{~L} 1196 \mathrm{M}$ mutation and the third-generation drug for the EGFR T790M mutation are approved for some instances of resistance after TKI treatment [36, 37]. Screening of drug-resistant mutations by rebiopsy is difficult and hinders the use of new-generation molecular targeted therapies. Hence, liquid biopsy is the optimal choice in the future. However, cfDNA detection is difficult in treated patients. Tumor cannot be accurately genotyped if the patient presents several metastatic lesions.

In this study, we performed digital PCR and sequence analysis in four patients (cases 12, 15, 16, and 17) that were diagnosed with NSCLC bearing EGFR mutations and underwent TKI treatment. These patients received SRS with CyberKnife to treat brain metastasis as a result of treatment failure or emergence of drug resistance. In previous studies, cfDNA analysis showed increased drug-resistant mutations in the plasma of patients with a failed TKI treatment [38, 39]. The predominant drug-resistant mutation in NSCLC patients is EGFR T790M. Our study detected EGFR T790M mutation in two out of the four patients. Most patients with NSCLC are associated with brain metastasis and undergo radiotherapy with or without TKI treatment [40]. In patients treated with SRS for brain metastasis, active lesions are found only in the brain, and the number of metastases is limited to $4-10$. Our study demonstrates that radiotherapy in such patients enables detection of tumorassociated gene mutations in the cfDNA samples.

When local failure occurs during systemic chemotherapy, radiotherapy is preferred for palliative care. Our study suggests that cfDNA detection combined with radiotherapy could replace rebiopsy to determine the tumor genotype.

Leon et al. and Cheg et al. evaluated total cfDNA levels using traditional irradiation methodology and suggested that irradiation induces cancer cell apoptosis, thereby increasing tumoral DNA in the plasma (Cancer Res. 1977 Mar; 37(3):646-50.) [41, 42]. In traditional radiotherapy, irradiation field includes the lymph region and the large blood vessel, which results in the apoptosis of lymphocytes in the blood vessels at a dose of around 2 Gy [43]. This increases total cfDNA, but hinders sequencing of tumor-derived DNA. We performed pinpoint irradiation which can avoid such hematopoietic cell bias (Supplementary Figure 1) the cancer tissue using stereotactic radiosurgery (SRS) and stereotactic radiotherapy (SRT) and confirmed tumoral cfDNA by digital PCR and sequence analysis. While our study speculates that the tumoral cfDNA was derived from apoptotic tumor cells, we confirm that irradiation 
increases tumoral cfDNA substantially. Importantly, we also clarified the time course of cfDNA elevation with clinical dose irradiation. The time course of apoptosis with irradiation is investigated previously in cell line and animal experiment, however the dose and fraction are clearly different as is described in introduction.

CfDNA analysis was approved by Food and Drug Administration (FDA) in 2017 and has been used clinically for diagnostic and prognostic applications. Our study investigated the influence of radiation on cfDNA quantity and composition.

Our study has several limitations. First, we performed digital PCR and targeted sequencing in a single experiment because of low recovery. Second, the sample size in our study was small. For that reason, we cannot completely exclude the possibility of technical error. However, to overcome clinical and biological bias, we selected only cases that were treated using pinpoint
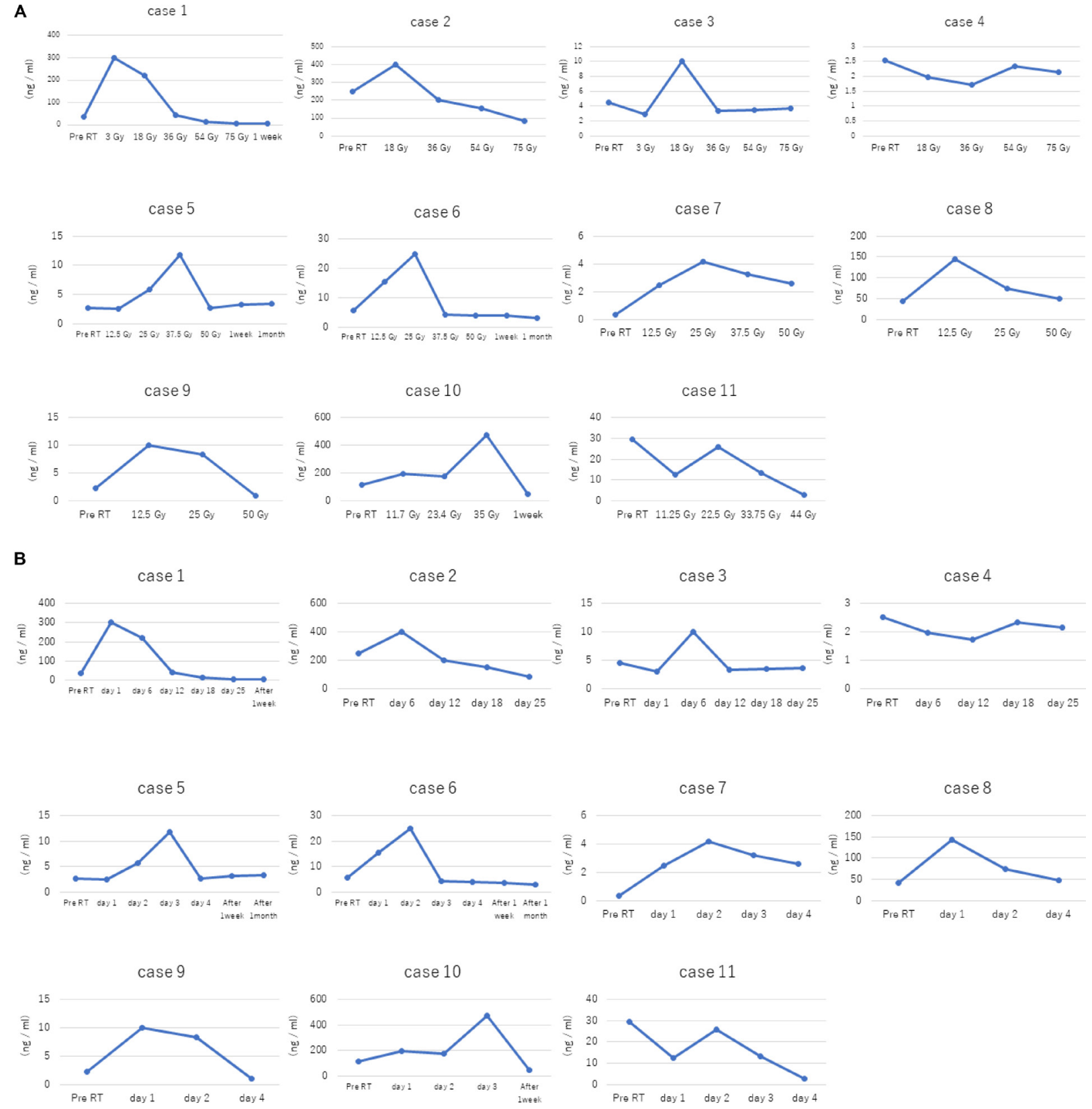

Figure 2: Dose- and time-dependent increase in plasma cfDNA levels in stage I NSCLC patients in response to radiotherapy. (A) Plasma cfDNA levels in stage I NSCLC patients (cases 1-11) in response to different irradiation doses are shown. In general, total cfDNA levels increase in response to radiotherapy. (B) Plots show time course of plasma cfDNA levels in stage I NSCLC patients (cases 1-11) before (pre-RT) and after radiation therapy. As shown, increased total cfDNA levels are observed at $24 \mathrm{~h}$ after radiation therapy. 
irradiation methods to avoid normal tissue contamination and chemotherapy effects. We also performed daily blood tests during radiotherapy and analyzed the digital PCR and targeted sequencing. We conclude that our results reflect tumor cfDNA kinetics during and after irradiation in the 17 NSCLC patients.

Our study demonstrates that radiotherapy increases total and tumoral cfDNA levels in earlystage and advanced stage NSCLC patients. Moreover, we demonstrate the utility of tumoral cfDNA analysis after irradiation for assessing drug-resistant mutations, which can help when preparing strategies for subsequent molecular targeted therapy.

\section{MATERIALS AND METHODS}

\section{Study design and patients}

The study protocols were carried out as approved by the Ethics committee of the Tokyo Metropolitan Cancer and Infectious Diseases Centre at Komagome Hospital (\#2013-1233). We obtained written informed consent from all the study subjects for the use of blood and resected tumor tissue for research purposes. All samples and medical data used in this study were anonymous to protect patient information.

We enrolled 17 patients diagnosed with NSCLC between July 2013 and July 2015 at the Komagome hospital. The patients underwent curative or palliative radiotherapy. The main endpoint of this study was to evaluate cfDNA levels after radiotherapy. Tumors were diagnosed as NSCLC based on the histopathology of biopsy specimens and the patients were graded according to the classification of the Union for International Cancer Control 7th edition. Tumor genotyping was performed by PCR. The clinicopathological features of the patients are summarized in Table 1.

As shown in Figure 1, blood samples were obtained from all patients just prior to radiotherapy (preradiotherapy or pre-RT) or a day after the first radiotherapy
A
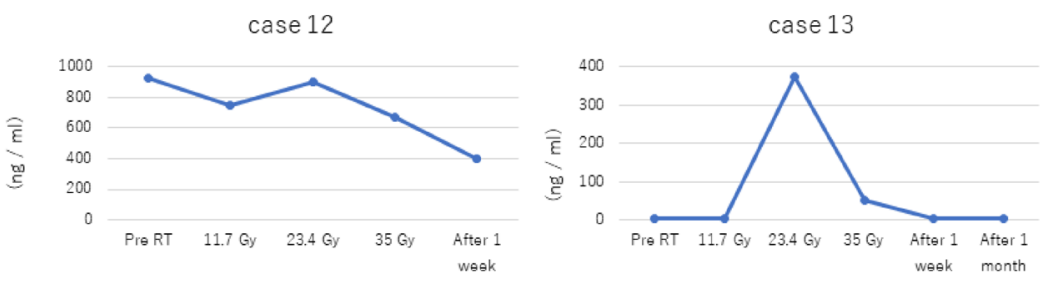

case 15

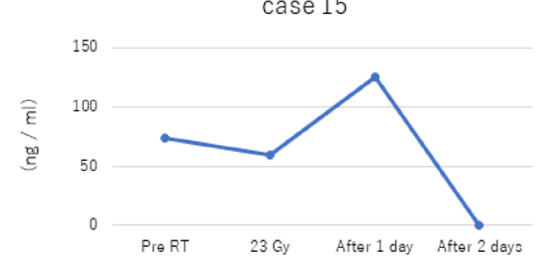

B
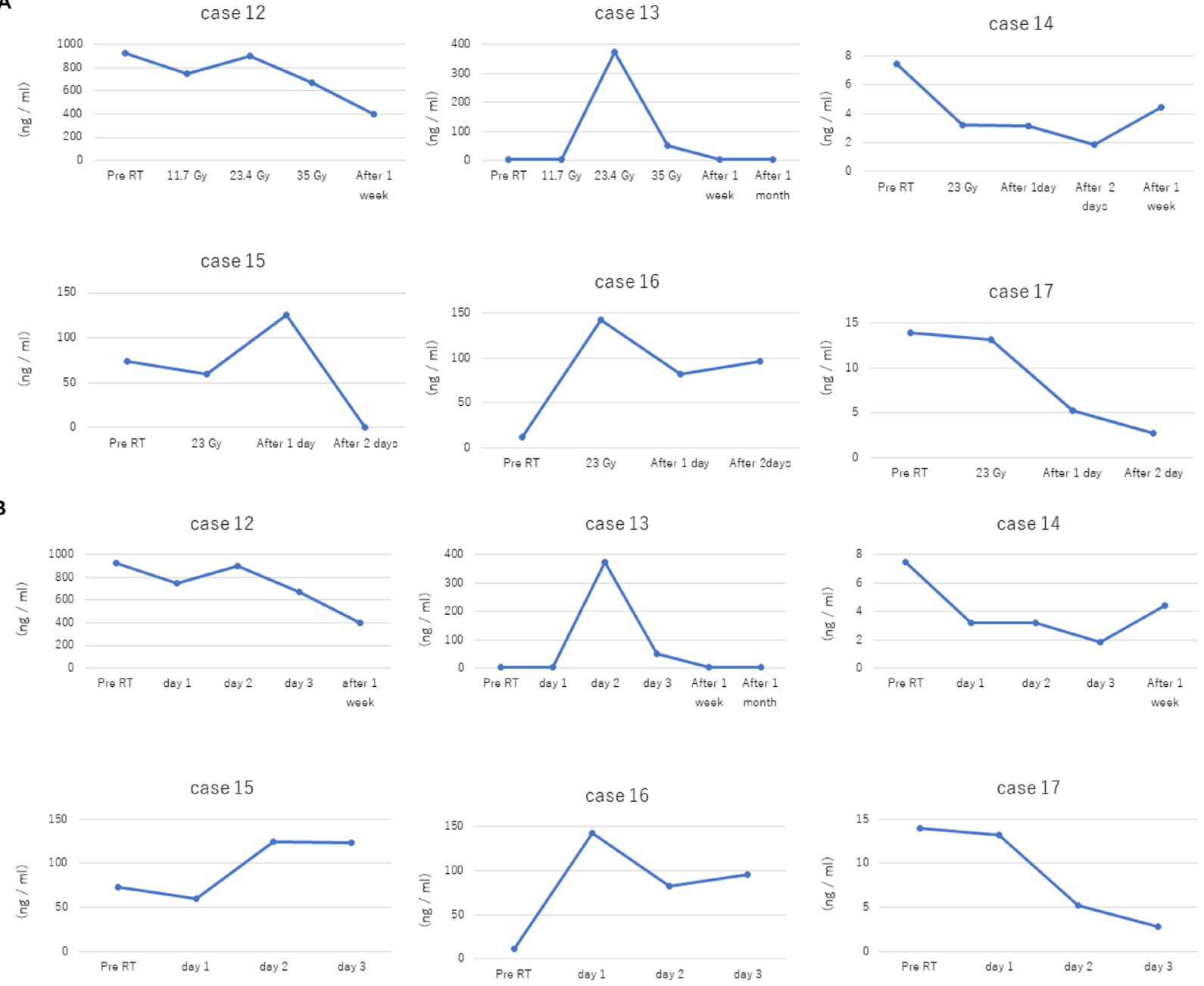

Figure 3: Dose- and time-dependent increase in plasma cfDNA levels in stage IV NSCLC patients in response to radiotherapy. (A) Plasma cfDNA levels in stage IV NSCLC patients (cases 12-17) in response to different irradiation doses are shown. (B) Plots show time course of plasma cfDNA levels in stage IV NSCLC patients (cases 12-17) before (pre-RT) and after radiation therapy. 

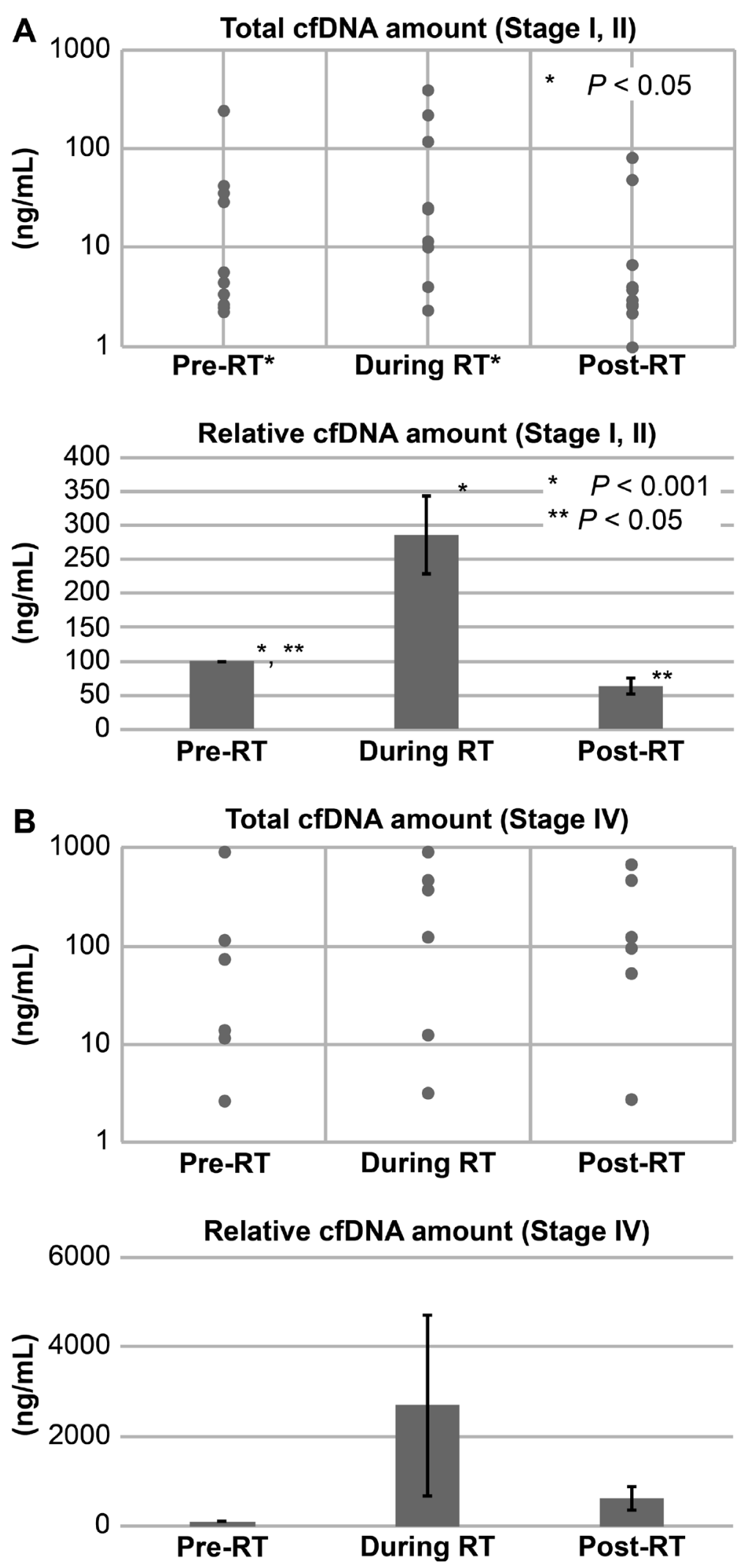

Figure 4: Total and relative cfDNA levels in stage I and IV NSCLC patients before and after radiotherapy. Total and relative cfDNA levels in (A) stage I-II and (B) stage IV NSCLC patients at pre-RT, during RT and post-RT is shown. Note: Continuous variables were compared using Student's $t$-test and $P<0.05$ was considered statistically significant compared to pre-RT; RT, radiotherapy. 
Table 2: Comparison of allele frequencies of EGFR mutations in cfDNA samples of NSCLC patients as determined by digital PCR and targeted sequencing

\begin{tabular}{|c|c|c|c|c|c|}
\hline Case No & $\begin{array}{c}E G F R \\
\text { mutation }\end{array}$ & $\begin{array}{l}\text { Allele frequency in } \\
\text { pre-RT by digital } \\
\text { PCR (copy/mL) }\end{array}$ & $\begin{array}{l}\text { Allele frequency during } \\
\text { RT by digital PCR } \\
\text { (copy } / \mathrm{mL})\end{array}$ & $\begin{array}{l}\text { Allele frequency in } \\
\text { pre-RT by targeted } \\
\text { sequencing }\end{array}$ & $\begin{array}{l}\text { Allele frequency } \\
\text { during RT by } \\
\text { targeted sequencing }\end{array}$ \\
\hline case 1 & - & - & - & N.D. & $7.8 \%(\mathrm{G} 719 \mathrm{C})$ \\
\hline case 2 & L858R & N.D (0) & $0.9 \%(10562)$ & N.D. & $0.5 \%$ \\
\hline case 12 & $\begin{array}{c}\text { exon } 19 \\
\text { del. }\end{array}$ & $0.2 \%(20866)$ & $0.4 \%(139579)$ & N.D. & N.D. \\
\hline \multirow[t]{2}{*}{ case 15} & L858R & $44194(0 \cdot 5 \%)$ & $2.3 \%(363269)$ & $0.3 \%$ & $1.5 \%$ \\
\hline & T790M & N.D. (0) & $0.4 \%(40824)$ & N.D. & $0.3 \%$ \\
\hline \multirow[t]{2}{*}{ case 16} & L858R & (N.D.) & $0 \cdot 2 \%$ & N.D. & $2.8 \%$ \\
\hline & L747S & - & - & N.D. & $2.3 \%$ \\
\hline case 17 & $\begin{array}{c}\text { exon } 19 \\
\text { del. }\end{array}$ & N.D. (64282) & $6.4 \%(2122718)$ & $0.3 \%$ & $7.3 \%$ \\
\hline
\end{tabular}

Note: del., deletion; N.D., not determined; RT, radiotherapy.

session and a day after administration of $1 / 4,1 / 2$, and $3 / 4$ of the total dose (during radiotherapy or RT) and at the end of the radiation regimen and at the first week and first month after radiotherapy (post-radiotherapy, post-RT). Among the seventeen enrolled patients that underwent radiotherapy, eleven were stage I-II NSCLC patients that rejected surgery and opted for radiotherapy. The remaining six stage IV NSCLC patients were diagnosed as EGFR mutation positive and presented with brain metastasis after TKI treatment failed.

\section{Radiotherapy}

We used the computed tomography (CT) datasets for these patients, including fully delineated targets and organs-at-risk (OAR) to strategize subsequent radiotherapy. The treatment plans included a prescribed dose of $50 \mathrm{~Gy} / 4$ fr or $75 \mathrm{~Gy} / 25$ fr for primary stage III NSCLC patients and $23 \mathrm{~Gy} / 1 \mathrm{fr}$ or $35 \mathrm{~Gy} / 3$ fr to treat NSCLC patients with brain metastasis. We reduced the radiation dose to $45 \mathrm{~Gy} / 4 \mathrm{fr}$ in case 11 to avoid complications because of OAR. For stage IV disease, we performed only stereotactic radiosurgery (SRS) to the brain and did not use radiation therapy at other sites.

We prescribed $50 \mathrm{~Gy} / 4 \mathrm{fr}$ SBRT for NSCLC patients with negative lymph nodes of $3 \mathrm{~cm}$ or less and threedimensional (3D) conformal radiotherapy (3D-CRT) at 75 Gy/25 fr for patients with $3-5 \mathrm{~cm}$ tumors in the primary site with adjacent risk organs. The doses were determined according to standard rules as is described in the National Comprehensive Cancer Network (NCCN) and Japan guideline. Stereotactic body irradiation therapy (SBRT) to the brain was performed using Cyber Knife (Accuray,
Tokyo, Japan), and radiation treatment of the lungs was performed using Vero4DRT (Mitsubishi, Tokyo, Japan) (Supplementary Figure 1).

\section{Plasma collection}

Whole blood was collected in 7-mL vacutainer tubes containing EDTA and centrifuged for $5 \mathrm{~min}$ at $800 \times \mathrm{g}$. Cleared plasma was stored in cryostat tubes at $-80^{\circ} \mathrm{C}$ until use. Plasma isolation was performed within $30 \mathrm{~min}$ of blood collection to prevent DNA contamination from blood cells.

\section{CfDNA extraction}

We concentrated $1 \mathrm{~mL}$ patient plasma using Maxwell rapid sample concentrator (Promega, Madison, WI, USA) and extracted nucleic acids using the Maxwell blood purification kit (AS1480; Promega, Madison, WI, USA) according to the manufacturer's instructions. DNA was purified using the QIAamp Circulating Nucleic Acid Kit (55114; Qiagen, Inc., Valencia, CA, USA) according to the manufacturer's instructions. We eluted the DNA in $50 \mu \mathrm{L}$ double distilled water and stored at $-20^{\circ} \mathrm{C}$. The DNA concentration was quantified with a Quantus fluorometer (Promega, Madison, WI, USA) following the manufacturer's instructions.

\section{Digital quantitative PCR}

Allele-specific qRT-PCR was performed in a LightCycler 480 Real-Time PCR System (Roche Holding AG., Basel, Switzerland). We determined the copy number 
of mutant and wild-type alleles of EGFR, EGFR exon 19 deletion as well as EGFR L858R and T790M mutations using a TaqMan SNP Genotyping kit (Thermo Fisher, Waltham, MA, USA) according to the manufacturer's instructions (10 ng of cfDNA per reaction). Patient and standard samples were processed in duplicates, and the mean cycle threshold $(\mathrm{Ct})$ value of duplicates was determined. The percentage of mutant EGFR alleles was calculated as the ratio of the copy number of mutant $E G F R$ relative to the total copy number of $E G F R$ (wild-type and mutant).

\section{CfDNA sequencing and analysis}

For the sequencing assays, we used two commercial and validated panels: the Ion AmpliSeq Cancer Hotspot Panel v2 and the Ion AmpliSeq Colon and Lung Cancer Panel [26]. The Ion AmpliSeq Cancer Hotspot Panel v2 was designed to amplify 207 amplicons covering approximately 2800 COSMIC mutations from 50 oncogenes and tumor-suppressor genes, whereas, the Ion AmpliSeq Colon and Lung Cancer Panel evaluated 22 genes that are implicated in colon and lung cancers. We generated barcoded libraries using $3 \mathrm{ng}$ each of cfDNA and the Ion AmpliSeq library preparation kit v2.0 (Life Technologies, Carlsbad, CA, USA). The samples were quantified using the Agilent 2100 Bioanalyser and Qubit 2.0 Fluorometer (Life Technologies), diluted to a final concentration of $10 \mathrm{pM}$ for template preparation using the OneTouch 2 instrument and Ion One Touch Template kit v2 (Life Technologies, Carlsbad, CA, USA). The quality of the resulting pooled libraries was checked using the Ion Sphere quality control Kit in a Qubit 2.0 Fluorometer. Libraries that passed quality control tests were sequenced on a PGM Ion Torrent (Life Technologies) using the PGM 200 sequencing kit v2 and 318 Chip v2. We pooled 16 libraries to achieve $500 \times$ coverage per target amplicon.

We aligned FASTQs to the human genome (hg19), and identified point mutations using Torrent Suite Software v3.0 and the Ion Torrent Variant Caller v4.0 Plug-in using somatic high stringency parameters and the targeted and hotspot pipelines. We set a 5\% allele frequency (AF) threshold and a $500 \times$ minimum coverage to identify de novo mutations; we also selected $0.1 \% \mathrm{AF}$ to identify previously characterized mutations during treatment [27]. All identified variants were confirmed using IGV 2.3 (Broad Institute).

\section{Statistical analysis}

We used Student's $t$-test to compare cfDNA amounts at pretreatment versus the highest point under radiotherapy with EZR [44] and the final point as post-radiotherapy.

\section{Author contributions}

S-IK, KN, KK, TS, and FK conducted the experiments and radiotherapy; S-IK, KT, TA, and SK wrote the manuscript; S-IK, HH, SY, and AM prepared the figures for the manuscript.

\section{ACKNOWLEDGMENTS}

This study was funded by the Grants-in-Aid for Scientific Research KAKENHI (multi-year fund).

\section{CONFLICTS OF INTEREST}

The authors declare that there are no conflicts of interest.

\section{REFERENCES}

1. Schwarzenbach H, Hoon DS, Pantel K. Cell-free nucleic acids as biomarkers in cancer patients. Nat Rev Cancer. 2011; 11: 426-37. https://doi.org/10.1038/nrc3066.

2. Mok T, Wu YL, Lee JS, Yu CJ, Sriuranpong V, SandovalTan J, Ladrera G, Thongprasert S, Srimuninnimit V, Liao M, Zhu Y, Zhou C, Fuerte F, et al. Detection and dynamic changes of egfr mutations from circulating tumor DNA as a predictor of survival outcomes in NSCLC patients treated with first-line intercalated erlotinib and chemotherapy. Clin Cancer Res. 2015; 21:3196-203. https://doi. org/10.1158/1078-0432.Ccr-14-2594.

3. Abolhassani M, Tillotson J, Chiao J. Characterization of the release of DNA by a human leukemia-cell line hl-60. Int J Oncol. 1994; 4:417-21.

4. Jahr S, Hentze H, Englisch S, Hardt D, Fackelmayer FO, Hesch RD, Knippers R. DNA fragments in the blood plasma of cancer patients: quantitations and evidence for their origin from apoptotic and necrotic cells. Cancer Res. 2001; 61:1659-65.

5. Stroun M, Lyautey J, Lederrey C, Olson-Sand A, Anker P. About the possible origin and mechanism of circulating DNA apoptosis and active DNA release. Clin Chim Acta. 2001; 313:139-42.

6. Wan JCM, Massie C, Garcia-Corbacho J, Mouliere F, Brenton JD, Caldas C, Pacey S, Baird R, Rosenfeld N. Liquid biopsies come of age: towards implementation of circulating tumour DNA. Nat Rev Cancer. 2017; 17:22338. https://doi.org/10.1038/nrc.2017.7.

7. Diehl F, Schmidt K, Choti MA, Romans K, Goodman S, Li M, Thornton K, Agrawal N, Sokoll L, Szabo SA, Kinzler KW, Vogelstein B, Diaz LA Jr. Circulating mutant DNA to assess tumor dynamics. Nat Med. 2008; 14:985-90. https://doi. org/10.1038/nm.1789.

8. Jiang T, Ren S, Zhou C. Role of circulating-tumor DNA analysis in non-small cell lung cancer. Lung Cancer. 2015; 90:128-34. https://doi.org/10.1016/j.lungcan.2015.09.013.

9. Chan KC, Jiang P, Chan CW, Sun K, Wong J, Hui EP, Chan SL, Chan WC, Hui DS, Ng SS, Chan HL, Wong $\mathrm{CS}$, Ma BB, et al. Noninvasive detection of cancerassociated genome-wide hypomethylation and copy 
number aberrations by plasma DNA bisulfite sequencing. Proc Natl Acad Sci U S A. 2013; 110:18761-8. https://doi. org/10.1073/pnas.1313995110.

10. Yu SC, Lee SW, Jiang P, Leung TY, Chan KC, Chiu RW, Lo YM. High-resolution profiling of fetal DNA clearance from maternal plasma by massively parallel sequencing. Clin Chem. 2013; 59:1228-37. https://doi.org/10.1373/ clinchem.2013.203679.

11. Qin Z, Ljubimov VA, Zhou C, Tong Y, Liang J. Cell-free circulating tumor DNA in cancer. Chin J Cancer. 2016; 35: 36. https://doi.org/10.1186/s40880-016-0092-4.

12. Mouliere F, El Messaoudi S, Pang D, Dritschilo A, Thierry AR. Multi-marker analysis of circulating cell-free DNA toward personalized medicine for colorectal cancer. Mol Oncol. 2014; 8:927-41. https://doi.org/10.1016/j. molonc.2014.02.005.

13. Lo YM, Zhang J, Leung TN, Lau TK, Chang AM, Hjelm NM. Rapid clearance of fetal DNA from maternal plasma. Am J Hum Genet. 1999; 64:218-24. https://doi. org/10.1086/302205.

14. Uchida J, Kato K, Kukita Y, Kumagai T, Nishino K, Daga H, Nagatomo I, Inoue T, Kimura M, Oba S, Ito Y, Takeda K, Imamura F. Diagnostic accuracy of noninvasive genotyping of EGFR in lung cancer patients by deep sequencing of plasma cell-free DNA. Clin Chem. 2015; 61:1191-6. https://doi.org/10.1373/clinchem.2015.241414.

15. Zhang Y, Xu Y, Zhong W, Zhao J, Chen M, Zhang L, Li L, Wang M. Total DNA input is a crucial determinant of the sensitivity of plasma cell-free DNA EGFR mutation detection using droplet digital PCR. Oncotarget. 2017; 8:5861-73. https://doi.org/10.18632/oncotarget.14390.

16. Paweletz CP, Sacher AG, Raymond CK, Alden RS, O'Connell A, Mach SL, Kuang Y, Gandhi L, Kirschmeier P, English JM, Lim LP, Janne PA, Oxnard GR. Biascorrected targeted next-generation sequencing for rapid, multiplexed detection of actionable alterations in cell-free DNA from advanced lung cancer patients. Clin Cancer Res. 2016; 22:915-22. https://doi.org/10.1158/1078-0432. Ccr-15-1627-t.

17. Volik S, Alcaide M, Morin RD, Collins C. Cell-free DNA (cfDNA): Clinical significance and utility in cancer shaped by emerging technologies. Mol Cancer Res. 2016; 14:898-908. https://doi.org/10.1158/1541-7786.Mcr-16-0044.

18. Takai E, Totoki Y, Nakamura H, Morizane C, Nara S, Hama N, Suzuki M, Furukawa E, Kato M, Hayashi H, Kohno T, Ueno H, Shimada K, et al. Clinical utility of circulating tumor DNA for molecular assessment in pancreatic cancer. Sci Rep. 2015; 5:18425. https://doi.org/10.1038/srep18425.

19. Chen KZ, Lou F, Yang F, Zhang JB, Ye H, Chen W, Guan T, Zhao MY, Su XX, Shi R, Jones L, Huang XF, Chen SY, et al. Circulating tumor DNA detection in early-stage nonsmall cell lung cancer patients by targeted sequencing. Sci Rep. 2016; 6:31985. https://doi.org/10.1038/srep31985.
20. Tinhofer I, Hristozova T, Stromberger C, Keilhoiz U, Budach V. Monitoring of circulating tumor cells and their expression of EGFR/phospho-EGFR during combined radiotherapy regimens in locally advanced squamous cell carcinoma of the head and neck. Int J Radiat Oncol Biol Phys. 2012; 83:e685-90. https://doi.org/10.1016/j.ijrobp.2012.02.009.

21. Bowen C, Spiegel S, Gelmann EP. Radiation-induced apoptosis mediated by retinoblastoma protein. Cancer Res. 1998; 58:3275-81.

22. Baatout S, Derradji H, Jacquet P, Ooms D, Michaux A, Mergeay M. Enhanced radiation-induced apoptosis of cancer cell lines after treatment with resveratrol. Int J Mol Med. 2004; 13:895-902.

23. Victory K, Burd R, Fribley A, Sittadjody S, Arnett D, Klein $\mathrm{RR}$, Limesand KH. Head and neck tumor cell radiation response occurs in the presence of IGF1. J Dent Res. 2011; 90:347-52. https://doi.org/10.1177/0022034510388037.

24. Phelps D, Bondra K, Seum S, Chronowski C, Leasure J, Kurmasheva RT, Middleton S, Wang D, Mo X, Houghton PJ. Inhibition of MDM2 by RG7388 confers hypersensitivity to X-radiation in xenograft models of childhood sarcoma. Pediatr Blood Cancer. 2015; 62:134552. https://doi.org/10.1002/pbc.25465.

25. Yard BD, Adams DJ, Chie EK, Tamayo P, Battaglia JS, Gopal P, Rogacki K, Pearson BE, Phillips J, Raymond DP, Pennell NA, Almeida F, Cheah JH, et al. A genetic basis for the variation in the vulnerability of cancer to DNA damage. Nat Commun. 2016; 7: 11428. https://doi.org/10.1038/ ncomms 11428.

26. Baker S, Dahele M, Lagerwaard FJ, Senan S. A critical review of recent developments in radiotherapy for nonsmall cell lung cancer. Radiat Oncol. 2016; 11: 115. https:// doi.org/10.1186/s13014-016-0693-8.

27. Tsang MW. Stereotactic body radiotherapy: current strategies and future development. J Thorac Dis. 2016; 8: S517-27. https://doi.org/10.21037/jtd.2016.03.14.

28. Lutz ST, Jones J, Chow E. Role of radiation therapy in palliative care of the patient with cancer. J Clin Oncol. 2014; 32:2913-9. https://doi.org/10.1200/jco.2014.55.1143.

29. Chow E, Harris K, Fan G, Tsao M, Sze WM. Palliative radiotherapy trials for bone metastases: a systematic review. J Clin Oncol. 2007; 25:1423-36. https://doi.org/10.1200/ jco.2006.09.5281.

30. Ma JT, Zheng JH, Han CB, Guo QY. Meta-analysis comparing higher and lower dose radiotherapy for palliation in locally advanced lung cancer. Cancer Sci. 2014; 105:1015-22. https://doi.org/10.1111/cas.12466.

31. McIlroy D, Sakahira H, Talanian RV, Nagata S. Involvement of caspase 3-activated DNase in internucleosomal DNA cleavage induced by diverse apoptotic stimuli. Oncogene. 1999; 18:4401-8. https://doi.org/10.1038/sj.onc.1202868.

32. Chang JY, Senan S, Paul MA, Mehran RJ, Louie AV, Balter P, Groen HJ, McRae SE, Widder J, Feng L, van den 
Borne BE, Munsell MF, Hurkmans C, et al. Stereotactic ablative radiotherapy versus lobectomy for operable stage I non-small-cell lung cancer: a pooled analysis of two randomised trials. Lancet Oncol. 2015; 16:630-7. https:// doi.org/10.1016/s1470-2045(15)70168-3.

33. Kanemoto A, Matsumoto Y, Sugita T. Timing and characteristics of radiation pneumonitis after stereotactic body radiotherapy for peripherally located stage I lung cancer. Int J Clin Oncol. 2015; 20:680-5. https://doi. org/10.1007/s10147-014-0766-3.

34. Tanaka K, Hida T, Oya Y, Oguri T, Yoshida T, Shimizu J, Horio Y, Hata A, Kaji R, Fujita S, Sekido Y, Kodaira T, Kokubo M, et al. EGFR mutation impact on definitive concurrent chemoradiation therapy for inoperable stage III adenocarcinoma. J Thorac Oncol. 2015; 10:1720-5. https:// doi.org/10.1097/jto.0000000000000675.

35. Yagishita S, Horinouchi H, Katsui Taniyama T, Nakamichi S, Kitazono S, Mizugaki H, Kanda S, Fujiwara Y, Nokihara H, Yamamoto N, Sumi M, Shiraishi K, Kohno T, et al. Epidermal growth factor receptor mutation is associated with longer local control after definitive chemoradiotherapy in patients with stage III nonsquamous non-small-cell lung cancer. Int J Radiat Oncol Biol Phys. 2015; 91:140-8. https://doi.org/10.1016/j.ijrobp.2014.08.344.

36. Jänne PA, Yang JC, Kim DW, Planchard D, Ohe Y, Ramalingam SS, Ahn MJ, Kim SW, Su WC, Horn L, Haggstrom D, Felip E, Kim JH, et al. AZD9291 in EGFR inhibitor-resistant non-small-cell lung cancer. N Engl J Med. 2015; 372:1689-99. https://doi.org/10.1056/ NEJMoa1411817.

37. Muller IB, De Langen AJ, Honeywell RJ, Giovannetti E, Peters GJ. Overcoming crizotinib resistance in ALKrearranged NSCLC with the second-generation ALKinhibitor ceritinib. Expert Rev Anticancer Ther. 2016; 16:147-57. https://doi.org/10.1586/14737140.2016.1131612.
38. Oxnard GR, Thress KS, Alden RS, Lawrance R, Paweletz CP, Cantarini M, Yang JC, Barrett JC, Janne PA. Association between plasma genotyping and outcomes of treatment with Osimertinib (AZD9291) in advanced non-small-cell lung cancer. J Clin Oncol. 2016; 34:3375-82. https://doi. org/10.1200/jco.2016.66.7162.

39. Yanagita M, Redig AJ, Paweletz CP, Dahlberg SE, O'Connell A, Feeney N, Taibi M, Boucher D, Oxnard GR, Johnson BE, Costa DB, Jackman DM, Janne PA. A prospective evaluation of circulating tumor cells and cell-free DNA in EGFR-mutant non-small cell lung cancer patients treated with Erlotinib on a Phase II Trial. Clin Cancer Res. 2016; 22:6010-20. https://doi. org/10.1158/1078-0432.Ccr-16-0909.

40. Cai L, Zhu JF, Zhang XW, Lin SX, Su XD, Lin P, Chen K, Zhang LJ. A comparative analysis of EGFR mutation status in association with the efficacy of TKI in combination with WBRT/SRS/surgery plus chemotherapy in brain metastasis from non-small cell lung cancer. J Neurooncol. 2014; 120:423-30. https://doi.org/10.1007/s11060-014-1570-7.

41. Cheng C, Omura-Minamisawa M, Kang Y, Hara T, Koike I, Inoue T. Quantification of circulating cell-free DNA in the plasma of cancer patients during radiation therapy. Cancer Sci. 2009; 100:303-9. https://doi. org/10.1111/j.1349-7006.2008.01021.x.

42. Leon SA, Shapiro B, Sklaroff DM, Yaros MJ. Free DNA in the serum of cancer patients and the effect of therapy. Cancer Res. 1977; 37:646-50.

43. Maisin JR. Protection against ionizing radiation by combinations of radioprotectors. Pharmacol Ther. 1988; 39:189-93.

44. Kanda Y. Investigation of the freely available easy-touse software 'EZR' for medical statistics. Bone Marrow Transplant. 2013; 48:452-8. https://doi.org/10.1038/ bmt.2012.244. 